\title{
Antiradical Activities and Cytotoxic Effects of Phlomis Brevibracteata Turrill on SK-HEP-1 Adenocarcinoma Cell Line ${ }^{+}$
}

\author{
Imge Kunter ${ }^{1, *}$, Niloofar Zabib ${ }^{1}$, Kelly Randmae ${ }^{2}$, Mahshid Dabeshlim ${ }^{1}$ and Muberra Kosar ${ }^{1}$ \\ 1 Faculty of Pharmacy, Eastern Mediterranean University, Famagusta, 99628, North Cyprus via Mersin 10, \\ Turkey; nzabib75@gmail.com (N.Z.); 127273@students.emu.edu.tr (M.D.); \\ muberra.kosar@emu.edu.tr (M.K.) \\ 2 Institute of Pharmacy, University of Tartu, 50411, Tartu, Estonia; kellirandmae@gmail.com \\ * Correspondence: imge.kunter@emu.edu.tr \\ + Presented at the 2nd International Cell Death Research Congress, İzmir, Turkey, 1-4 of November 2018. \\ Published: 6 December 2018
}

\begin{abstract}
The present study investigates the total phenol amount, radical scavenging and anticancer activity of methanolic extract of Phlomis brevibracteata Turrill (PBT) leaves; an endemic plant of North Cyprus. The antiradical activity and cytotoxicity of $70 \%$ methanolic extract of PBT leaves were analyzed by the implementation of DPPH, ABTS radical scavenging activity tests and MTT assay, respectively. Our results showed significant antiradical scavenging activity in the total phenolic content of the PBT leaves. MTT assay proved potent cytotoxic activity against SK-HEP-1 cell line not only for $70 \%$ methanolic extract of PBT, but also for gallic acid and caffeic acid constituents of the total phenolic extract.
\end{abstract}

Keywords: Phlomis brevibracteata Turrill; antiradical; cytotoxicity

\section{Introduction}

Medicinal plants have gained an increased attention to treat complications such as cancer by isolating the right active ingredients [1]. A recent estimation has claimed that out of 250,000 discovered plant species, one thousands of them show significant anticancer potency. Beside all the available anticancer medication in the market, the need of discovering novel medications with an improved efficacy and side-effect profile is still felt. The genus Phlomis includes up to 100 species that are distributed in Euroasia [2]. Of these species, Phlomis brevibracteata Turrill (PBT) is a plant from North-Cyprus which belongs to the family of Lamiaceae. The plant occurs in 16 places, it is classified as endemic and it is also in the Red List of Threatened Species [3]. P. brevibracteata grows between 100 and $1100 \mathrm{~m}$ above sea level in Mediterranean climate. In traditional medicine Phlomis plants have been used to treat diabetes, gastric ulcer, haemorrhoid, inflammation and to heal wounds [3]. Phlomis species are also known to have antidiabetic effects by reducing the oxidative stress, which in turn explains their hepatoprotective characteristics [4,5]. It is believed that flavonoids, iridoids, phenyl ethanoid/propanoid glycosides, essential oils, lignans, diterpenoids and alkaloids are the main phytochemicals responsible for the majority of the above-mentioned effects [4]. The aim of this study is to investigate radical scavenging activities and cytotoxicity effects of PBT on SK-HEP1 adenocarcinoma cell line by (DPPH•), ABTS+• and MTT assay, respectively. 


\section{Materials and Methods}

\subsection{Material Collection and Extract Preparation}

Air-dried PBT leaves were cut into small pieces and extracted with $70 \%$ methanol (x 3 ) at room temperature. Methanol was evaporated under vacuum $\left(40^{\circ} \mathrm{C}\right)$. Extracts were lyophilized and stored at $+4{ }^{\circ} \mathrm{C}$ until further analysis.

\subsection{Total Phenolics}

Total phenols were estimated as GAE, per gram of extract [5].

\subsection{1,1-Diphenyl-2-Picrylhydrazyl Radical (DPPH•) Scavenging Activity}

Extracts were dissolved in aqueous methanol, solutions were prepared between 0.01 and 1 $\mathrm{mg} / \mathrm{mL}$ concentrations. Each extract dilution was mixed with Tris- $\mathrm{HCl}$ buffer than $\mathrm{DPPH} \bullet$ in $\mathrm{MeOH}$ was added to all tubes. After $30 \mathrm{~min}$ absorbance was recorded at $517 \mathrm{~nm}$. The percentage inhibition was calculated using Eqn.1 (\%inhibition $=[($ Acontrol-Asample $) /($ Acontrol $)] \times 100)$. Estimated IC50 values were presented as the mean value of triplicate analyses.

\subsection{ABTS+• Radical Scavenging Activity}

The ABTS+ $\bullet$ radical and $\mathrm{K}_{2} \mathrm{~S}_{2} \mathrm{O}_{8}$ solution prepared. The absorbance was adjusted to 0.700 with water at $734 \mathrm{~nm}$. Extracts were prepared at 3 and $6 \mathrm{mg} / \mathrm{mL}$ concentrations. Standard Trolox stock solution was prepared at $0.1,0.5,1,1.5$, and $2 \mathrm{mM}$ concentrations. After ABTS+ $\bullet$ solution was added to the sample, the absorbance was measured at $734 \mathrm{~nm}$, at first and 30th minutes. Results are expressed as the Trolox equivalent antioxidant capacity (TEAC, mM Trolox).

\subsection{Cell Culture and MTT Assay}

Human Hepatic Adenocarcinoma cell line SK-HEP-1 were maintained in DMEM supplemented with $10 \% \mathrm{FBS}, 100 \mathrm{U} / \mathrm{mL}$ penicillin, $2 \mathrm{mM}$ L-glutamine, $100 \mathrm{mg} / \mathrm{mL}$ streptomycin and 1 X NEAA at $5 \% \mathrm{CO} 2$ at $37{ }^{\circ} \mathrm{C}$. MTT assay was used to determine the cytotoxic effects of methanolic extracts of PBM, gallic acid and caffeic acid on SK-HEP-1 cancer cell line for $48 \mathrm{hrs}$. Briefly, $5 \times 10^{3}$ cells were seeded in a 48 well plate, after overnight incubation. The, cells were then incubated with different concentrations of extract and standart containing medium. Following a 48-h treatment, MTT was added to the medium. Than formazan crystals were dissolved with DMSO and absorption was measured at $570 \mathrm{~nm}$. The cell viability was calculated as viable cell percentage.

\subsection{Statistical Analysis}

Experiments have been independently carried out three times, and all samples were presented as mean \pm SE from six measurements for cytotoxicity analysis, and as mean \pm SD for antioxidant assays. One way ANOVA test was used for analysis. $P<0.05$ was considered as statistically significant. IC50 (the median growth inhibitory concentration) values have been calculated from the dose response inhibition curve. All the analyses were performed using GraphPad Prism 5 software.

\section{Results}

\subsection{Antiradical Activity of PBM}

The PBT leaves were extracted using $70 \%$ methanol as a solvent and the yield of extract was found $11.79 \%$. Total phenol amount of PBT leaf extract was calculated as gallic acid equivalent (GAE) per gram extract. The total phenol amount of the extract was recorded $24.360 \mathrm{mgGAE} /$ gextract \pm 0.296 (mean $\pm \mathrm{SD}, n=6$ ). Depending on the concentrations, the extract managed to scavenge the DPPH• radical at physiological $\mathrm{pH}$. For both Figure 1a,b, linear correlations were found between concentration and absorbance/inhibition $(\mathrm{r} 2=0.9907)$. IC50 value of $70 \% \mathrm{MeOH}$ extract was also 
calculated using Equation 1 as $0.556 \mathrm{mg} / \mathrm{mL}$. Antiradical activity was found high since the $70 \% \mathrm{MeOH}$ extract is rich in phenolic components. PBM was also tested in ABTS+• assay, and the results are 2.29 \pm 0.10 and $0.81 \pm 0.31 \mathrm{TEAC}$ in $3 \mathrm{mg} / \mathrm{mL}$ and $6 \mathrm{mg} / \mathrm{mL}$ concentrations, respectively. The results revealed a significant antiradical activity mainly because of the high total phenolic content of PBM.

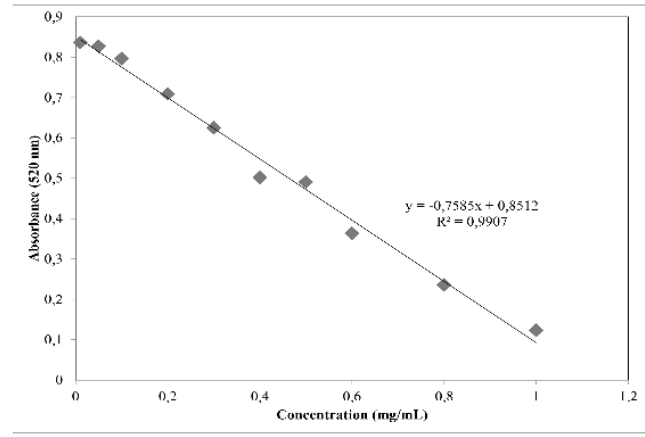

(a)

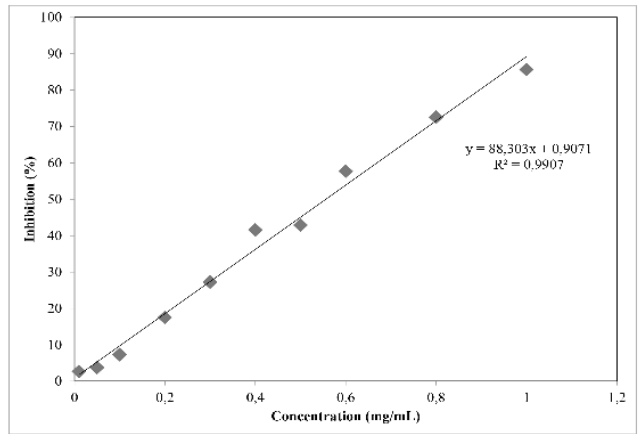

(b)

Figure 1. DPPH• scavenging activity analysis (a) Absorbance values of different concentration of extract (b) Inhibition values of different concentration of PBM in DPPH• scavenging assay.

\subsection{Cytotoxicity Effect of PBM on SK-HEP-1 Cell Line}

Cytotoxicity effect of PBM significantly increased in a concentration-dependent manner. At concentrations over $1000 \mathrm{ug} / \mathrm{mL}$, the cytotoxicity increased drastically as shown in Figure 2. $(p<$ 0.0001). The IC50 value of PBM was determined as $1056 \mathrm{ug} / \mathrm{mL}$.

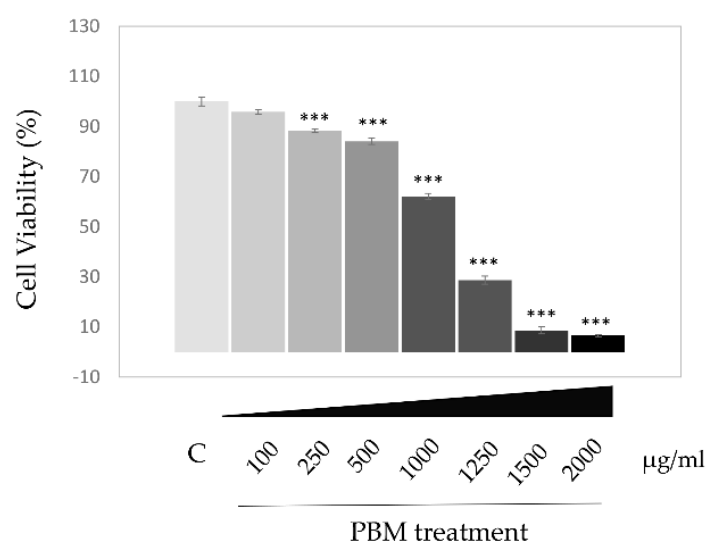

Figure 2. Cytotoxicity effect of different concentrations of PBM on SK-HEP-1 cell line. $\left.{ }^{* * *} p<0.0001\right)$

\subsection{Cytotoxicity Effect of Gallic acid and Caffeic Acid on SK-HEP-1 Cell Line}

As depicted in Figure 3a, each of the applied concentrations of gallic acid has a different level of cytotoxicity potency. Starting from $100 \mathrm{ug} / \mathrm{mL}$, the cytotoxicity became significant $\left({ }^{* *} p<0.001,{ }^{* * *} p<\right.$ $0.0001)$. In case of caffeic acid, cytotoxicity became significant after $250 \mathrm{ug} / \mathrm{mL}$ as shown in Figure $3 \mathrm{~b}$ $\left({ }^{* *} p<0.001,{ }^{* * *} p<0.0001\right)$. IC50 values were determined as $179 \mathrm{ug} / \mathrm{mL}$ and $319 \mathrm{ug} / \mathrm{mL}$ for gallic acid and caffeic acid, respectively. 


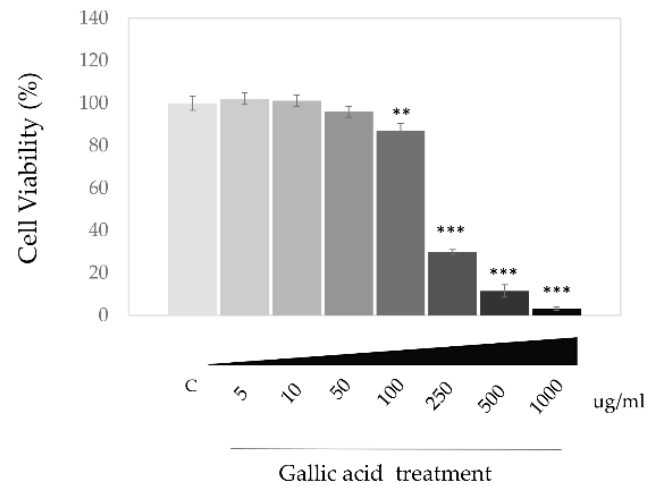

(a)

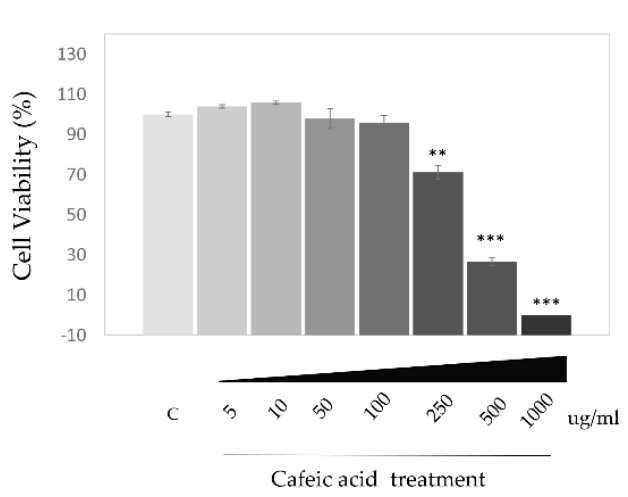

(b)

Figure 3. Cytotoxicity effect of gallic and caffeic acid on SK-HEP-1 cell line. (a) The effect of different concentrations of gallic acid (b) The effect of different concentrations of caffeic acid. ${ }^{* *} p<0.001,{ }^{* * *} p$ $<0.0001)$

\section{Discussion}

Although information about anticancerogenic and antiradical effects of Phlomis is available in to the best of our knowledge this is the only study analyzing the antioxidant activity and cytotoxicity effects of Cyprus endemic PBT [6]. Our findings have similarities with the literature in terms of antioxidant and cytotoxicity activities of Cyprus endemic Plomis. We believe that the antioxidant and anticancerogenic effects of PBT on SK-HEP-1 cell line are closely related to the phenolic constituents. In future studies, we plan to investigate the active constituents and molecular mechanisms of anticancerogenic effects. Overall, our results suggest that PBT is a good phytotherapy candidate.

Author Contributions: I.K. and M.K. conceived and designed the experiments; I.K, M.K, N.Z., K.R. and M.D. performed the experiments; and I.K. and M.K. analyzed the data; I.K, M.K. and N.Z. wrote the manuscript.

Acknowledgments: This research received no external funding. We would like to thank to Sami Tomson for his help in collectting Phlomis brevibracteata Turrill samples.

\section{References}

1. Mohajer, M.; Sarkhail, P.; Hajarolasvadi, N.; Zamani, M.; Khorasani, R.; Shafiee, A.; Amin, G.; Abdollahi, M. Anti-inflammatory and analgesic effects of Phlomis lanceolata Bioss. and Hohen. Extracts and examination of their components. Int. J. Pharmacol. 2006, 2, 50-54.

2. Fedorov, A.A. (Ed.) Flora of Russia, the European Part and Bordering Region; Timber Press: Portland, OR, USA, 2006; Volume 9.

3. Kadis, C.; Georghiou, K. Seed dispersal and germination behavior of three threatened endemic labiates of Cyprus. Plant Spec. Biol. 2010, 25, 77-84.

4. Amor, I.; Boubaker, J.; Sgaier, M.; Skandrani, I.; Bhouri, W.; Neffati, A.; Kilani, S.; Bouhlel, I.; Ghedira, K.; Chekir-Ghedira, L. Phytochemistry and biological activities of Phlomis species. J. Ethnopharmacol. 2009, 125, 183-202.

5. Singleton, V.L.; Orthofer, R.; Lamuela-Raventós, R.M. Analysis of total phenols and other oxidation substrates and antioxidants by means of folin- ciocalteu reagent. Methods Enzymol. 1998, 299, 152-178.

6. Sarkhail, P.; Sahranavard, S.; Nikan, M.; Gafari, S.; Eslami-Tehrani, B. Evaluation of the cytotoxic activity of extracts from six species of Phlomis genus. JAPS 2017, 7, 180-184.

(C) 2018 by the authors. Licensee MDPI, Basel, Switzerland. This article is an open access article distributed under the terms and conditions of the Creative Commons Attribution (CC BY) license (http://creativecommons.org/licenses/by/4.0/). 